\title{
Autologous Sarcoma Cell Lysate
}

National Cancer Institute

\section{Source}

National Cancer Institute. Autologous Sarcoma Cell Lysate. NCI Thesaurus. Code C105807.

A cell lysate derived from sarcoma cells with potential immunostimulatory and antineoplastic activities. Upon intradermal administration, the autologous sarcoma cell lysate exposes the immune system to an undefined amount of sarcoma-type tumor associated antigens (TAA), which may result in the induction of both specific anti-tumoral cytotoxic T lymphocytes (CTL) and antibody-dependent responses against the sarcoma TAA-expressing cells, resulting in sarcoma cell lysis. 